who felt safe to disclose their condition or felt supported by their institution or colleagues. Despite widening participation programmes, medicine can still be discriminatory towards those with disabilities. It would not be unreasonable to suppose that such reluctance to seek support or have the need for this recognised could be extrapolated to our patients.

The term disability is broad, both in nature and degree. This is often poorly reflected in medical guidelines, whereby our lack of understanding can contribute to the pre-existing stigma. The title of the General Medical Council's Welcomed and Valued ${ }^{4}$ guidance for those with disabilities in the medical profession gives the impression of framing inclusivity in a positive light. However, the persistent use of terms like 'support', 'student needs' or educators and institutions applying their 'duties' means the focus is on reducing discrimination and making reasonable adjustments to allow for an assessment of competence. The presumption is that disability may be a threat to competence and to patient safety. In fact, disability may give lived experience that improves competency through empathy and understanding. We need to start focusing on what such students, doctors, educators and, crucially, patients can add, not simply what they need.

If we provide a safe space for those with lived experience of disabilities to share their experiences and the impact on their life, then each one of us can improve our understanding. Indeed, more doctors being open about their visible and invisible disabilities mean more positive role models for students. Widening participation can then move from just implementing antidiscrimination legislation to appreciating the value that diversity adds and the grassroots barriers to entering and thriving in the profession of medicine. Every medical educator can contribute by providing a safe space for disclosure and a willingness to learn and be educated by our patients and students.

Elliott Carthy, University of Oxford, UK. Email: elliott.carthy@psych.ox.ac.uk

\section{Declaration of interest}

None

1 Department of Work \& Pensions. Family Resources Survey 2018/19. 2020. Available from: https://www.gov.uk/government/statistics/familyresources-survey-financial-year-201819 [cited 27 Dec 2020].

2 Shrewsbury D. Disability and participation in the professions: examples from higher and medical education. Disabil Soc 2015; 30(1): 87-100

3 British Medical Association. Disability in the Medical Profession. Available from: https://www.bma.org.uk/advice-and-support/nhs-delivery-andworkforce/workforce/disability-in-the-medical-profession [cited 27 Dec 2020].

4 General Medical Council. Welcomed and Valued: Supporting Disabled Learners in Medical Education and Training. Available from: https:// www.gmc-uk.org/education/standards-guidance-and-curricula/guidance/welcomed-and-valued [cited 27 Dec 2020].

doi:10.1192/bjb.2021.48
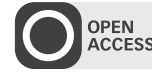

OPEN

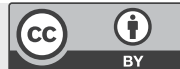

(c) The Author(s), 2021. Published by Cambridge University Press on behalf of the Royal College of Psychiatrists. . This is an Open Access article, distributed under the terms of the Creative Commons Attribution licence (http://creativecommons.org/licenses/by/4.0/), which permits unrestricted re-use, distribution, and reproduction in any medium, provided the original work is properly cited.

\section{More research needed into long-term medical student mental health during COVID-19 pandemic and beyond}

The mental health of healthcare professionals has been significantly affected by the COVID-19 pandemic. ${ }^{1}$ We believe that more research focusing specifically on the long-term mental health of medical students is required. Medical students are an at-risk group, with a greater incidence of anxiety ${ }^{2}$ than the general population, and a higher prevalence of suicidal ideation than physicians and nurses. ${ }^{3}$ The risk is further compounded by being young, ${ }^{1}$ having higher awareness of disease severity, and possessing common personality traits such as maladaptive perfectionism and difficulty adapting to disruption in routine. ${ }^{2}$

Medical students often face a sense of duty to volunteer in hospitals in times of global health emergencies such as the current pandemic, which can bring particular emotional challenges. The subsequent higher risk of transmitting COVID-19 may cause increased social isolation. Uncertainty around medical education due to cancelled exams and placements also increases stress. ${ }^{4}$

Although a recent meta-analysis showed no difference in anxiety during COVID-19 in medical students, ${ }^{2}$ isolated studies worldwide have shown increased anxiety in those whose loved ones had contracted COVID-19 and who had interacted with COVID-19 patients. ${ }^{4}$

Higher levels of baseline stress and depression are negative predictors of poor mental health, ${ }^{1}$ so more research must be done to identify those especially at risk. Those with preexisting mental health issues have reported decreased access to the usual support services during the pandemic. ${ }^{1}$ To our knowledge, there is no available literature exploring the impact of COVID-19 on medical students with pre-existing mental illness. Experiences in previous pandemics such as SARS show that long-term mental health issues such as alcohol misuse and post-traumatic stress symptoms can persist for several years in healthcare workers who have been quarantined or have worked in high-risk areas. ${ }^{5}$

The majority of current studies of mental health in COVID-19 have been cross-sectional, and few have focused on medical students. Longitudinal, large-scale, multi-country studies focusing on medical students of all age groups and investigating more variables, such as pre-existing mental illness, are required to identify those most at risk and the long-term effects on this population. The results of these studies could be used to improve future implementation of targeted medical student-specific mental healthcare interventions. ${ }^{1}$

Anusha Mahesh Prabhu, Imperial College London, UK. Email: anusha. prabhu@hotmail.com; Intishar Rashad, Armed Forces Medical College, Dhaka Cantonment, Dhaka-1206, Bangladesh. Email: intisharrashad@gmail. com

\section{Acknowledgments}

Both authors have contributed equally in preparing this article.

\section{Declaration of interest}

None 
1 Moreno C, Wykes T, Galderisi S, Nordentoft M, Crossley N, Jones N, et al. How mental health care should change as a consequence of the COVID-19 pandemic. Lancet Psychiatry 2020; 7(9): 813-24.

2 Lasheras I, Gracia-García P, Lipnicki DM, Bueno-Notivol J, López-Antón $\mathrm{R}$, de La Cámara $\mathrm{C}$, et al. Prevalence of anxiety in medical students during the COVID-19 pandemic: a rapid systematic review with meta-analysis. Int. J. Environ. Res. Public Health 2020; 17: 6603.

3 Que J, Shi L, Liu J, Gong Y, Sun Y, Mi W, et al. Prevalence of suicidal thoughts and behaviours among medical professionals: a meta-analysis and systematic review. Lancet 2019; 394: S11.

4 Saraswathi I, Saikarthik J, Senthil Kumar K, Srinivasinapan KM, Ardhanaari M, Gunapriya R. Impact of COVID-19 outbreak on the mental health status of undergraduate medical students in a COVID-19 treating medical college: a prospective longitudinal study. PeerJ 2020; 8: e10164.
5 Wu P, Liu X, Fang Y, Fan B, Fuller CJ, Guan Z, et al. Alcohol abuse/ dependence symptoms among hospital employees exposed to a SARS outbreak. Alcohol Alcohol 2008; 43(6): 706-12.

doi:10.1192/bjb.2021.49

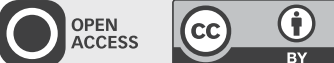

(C) The Author(s), 2021. Published by Cambridge University Press on behalf of the Royal College of Psychiatrists. . This is an Open Access article, distributed under the terms of the Creative Commons Attribution licence (http://creativecommons.org/licenses/by/4.0/), which permits unrestricted re-use, distribution, and reproduction in any medium, provided the original work is properly cited. 